\title{
РАЗВИТИЕ СЕЛЬСКОХОЗЯЙСТВЕННОЙ КООПЕРАЦИИ В РОССИИ
}

\author{
(c) 2021 Лебедев Александр Ларионович \\ кандидат технических наук, профессор, ректор \\ Международный экономико-гуманитарный институт, Россия, Москва \\ E-mail: a.lebedev@imegi.ru
}

(c) 2021 Пекуровский Дмитрий Александрович

кандидат ветеринарных наук, доцент кафедры управления АПК и сельскими территориями Российская академия кадрового обеспечения агропромышленного комплекса, Россия, Москва

E-mail: pekurovskii@mail.ru

\section{(c) 2021 Семикова Ольга Руслановна}

кандидат экономических наук, доцент, проректор по учебно-методической работе

Международный экономико-гуманитарный институт, Россия, Москва

E-mail: semikova@imegi.ru

Статья посвящена вопросам развития сельскохозяйственной кооперации в России. Автором рассмотрены такие проблемы, как отсутствие необходимых социальных институтов, низкая инициатива населения, недостаточный уровень государственной поддержки. Автор приходит к выводу о том, что при решении указанных проблем и увеличении числа кооперативов разных видов (производственных, обслуживающих, кредитных) возможно увеличение благосостояния фермеров, повышение самозанятости на селе и удовлетворение спроса городских жителей на фермерскую продукцию.

Ключевые слова: кооперация; кредитные кооперативы; сбыт сельскохозяйственной продукции; сельскохозяйственные кооперативы; фермерская продукция.

Сельскохозяйственная кооперация является одной из форм совместной деятельности фермеров. Кооперативное объединение позволяет объединить разрозненные фермерские хозяйства для решения различных вопросов, связанных с производством и сбытом продукции [12].

Несмотря на то, что идеи кооперативизма возникли еще в XIX веке, в настоящее время потребность в объединении сохраняется. Переход на капиталистические рельсы в конце XX века крайне негативно сказался на сельском хозяйстве, что выразилось в снижении численности выпускаемой продукции и в снижении поголовья скота [11]. Вместе с этим, жители села потеряли гарантированную ранее возможность сбыта продукции домохозяйств. Однако, если городские жители испытывали сложности с продовольствием, то жители села могли прокормиться за счет собственного домохозяйства. На рис. 1 представлена структура сельского хозяйства за период 1991-2019 годов. К концу 90-х годов более половины продукции выпускалось хозяйствами населения, одной из причин чему был глубокий кризис АПК.
Структура продукции сельского хозяйства по категориям хозяйств

Несмотря на большую в предыдущие два десятилетия роль хозяйств населения в производстве продукции сельского хозяйства, в России пока не сложилась устойчивая практика кооперации, что может быть объяснено следующими причинами:

- Повышение эффективности предприятий АПК (в том числе за счет инноваций);

- Повышение стоимости кормов, доступных населению (соответственно, снижение рентабельности фермерских хозяйств);

- Отсутствие налаженных каналов сбыта;

- Отсутствие инициативы населения.

Собственно, одной из главных причин слабого развития кооперативных форм является отсутствие инициативы. П.М. Лукичев указывает на «недостаточный социальный капитал кооперации на селе и отсутствие инициативы снизу. Низовое кооперативное движение в отличие, например, от дореволюционной кооперации, практически отсутствует» [4, с. 234]. Между тем, для развития кооперации на селе присутствует 


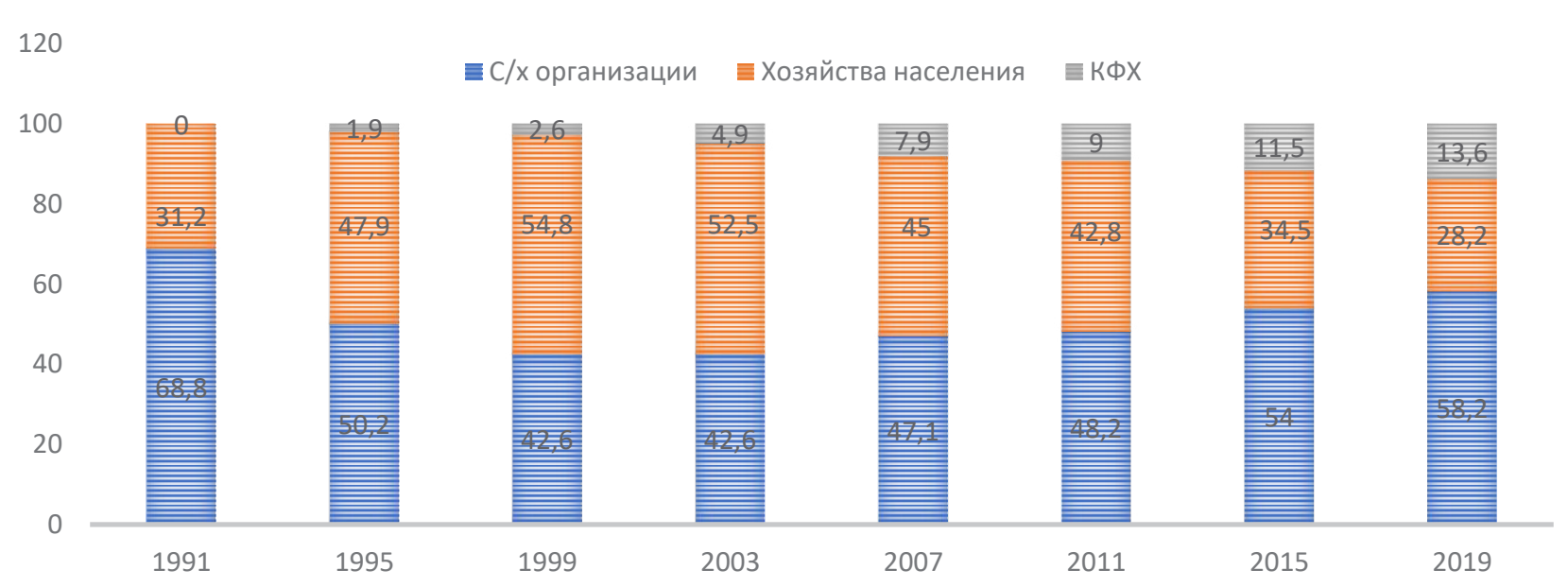

Puc. 1. Структура сельского хозяйства по категориям хозяйств по РФ за период 1991-2019 годы

необходимая нормативно-правовая база, также развитие кооперации является одной из приоритетных задач государственной политики. В ст. 1 Федерального закона «О сельскохозяйственной кооперации» от 08.12.1995 № 193-Ф3 [10] сельскохозяйственный кооператив определяется как организация, созданная сельскохозяйственными товаропроизводителями и (или) ведущими личные подсобные хозяйства гражданами на основе добровольного членства для совместной производственной или иной хозяйственной деятельности, основанной на объединении их имущественных паевых взносов в целях удовлетворения материальных и иных потребностей членов кооператива.

Формы сельскохозяйственного кооператива следующие:

- Сельскохозяйственный производственный кооператив;

- Сельскохозяйственный потребительский кооператив.

Непосредственную помощь в создании и ведении деятельности кооперативам представляют Центры компетенций в сфере сельскохозяйственной кооперации, которые создаются на региональном уровне. Одной из отличительных особенностей данных центров является наличие (как правило) стратегической программы деятельности и стандарта деятельности. Центры оказывают информационно-консультационные услуги физическим и юридическим лицами [8]. Центры компетенций действуют в 83 субъектах.

Основная часть работы по развитию сельскохозяйственных кооперативов (СХК) производится на региональном уровне. В 83 субъектах имеются комплексные программы по развитию кооперации (в 2017 году данные программы действовали только в 24 субъектах). Программы включают в себя правовые, финансовые, организационные, информационные меры поддержки, а также меры, направленные на организацию каналов сбыта фермерской продукции. За период 2018-2020 годов было вновь создано 2133 СХК, из которых 92\% являются потребительскими СКХ (соответственно, 8\% являются производственными кооперативами). Рост численности кооперативов сопряжен с ростом объемов продукции (рис. 2) [5]. Учитывается объем отгруженных товаров собственного производства, выполненные работы и оказанные услуги силами сельскохозяйственных потребительских кооперативов.

В 2019 году потребительскими СХК было выпущено продукции стоимостью 33,8 млрд. рублей. Необходимо отметить, что потребительские СХК, в отличие от производственных, имеют внутреннюю дифференциацию. Наиболее актуальная форма перерабатывающих кооперативов. K перерабатывающим кооперативам относятся потребительские кооперативы, занимающиеся переработкой сельскохозяйственной продукции (производство мясных, рыбных и молочных продуктов, хлебобулочных изделий, овощных и плодово-ягодных продуктов, изделий и полуфабрикатов изо льна, хлопка и конопли, лесо- и пиломатериалов и других). Большое экономическое значение потребительских СХК объясняется тем, что они являются наиболее близкой для сельских жителей формой совместной деятельности. А.А.Иншаков справедливо отмечает, что саму сферу сельскохозяйственного производства кооперация почти не затрагивает. Она затрагивает лишь отдельные операции - переработку, сбыт, хранение, транспортировка, упаковка, со- 
ПРОДУКЦИЯ СХК

(МЛРД. РУБ)

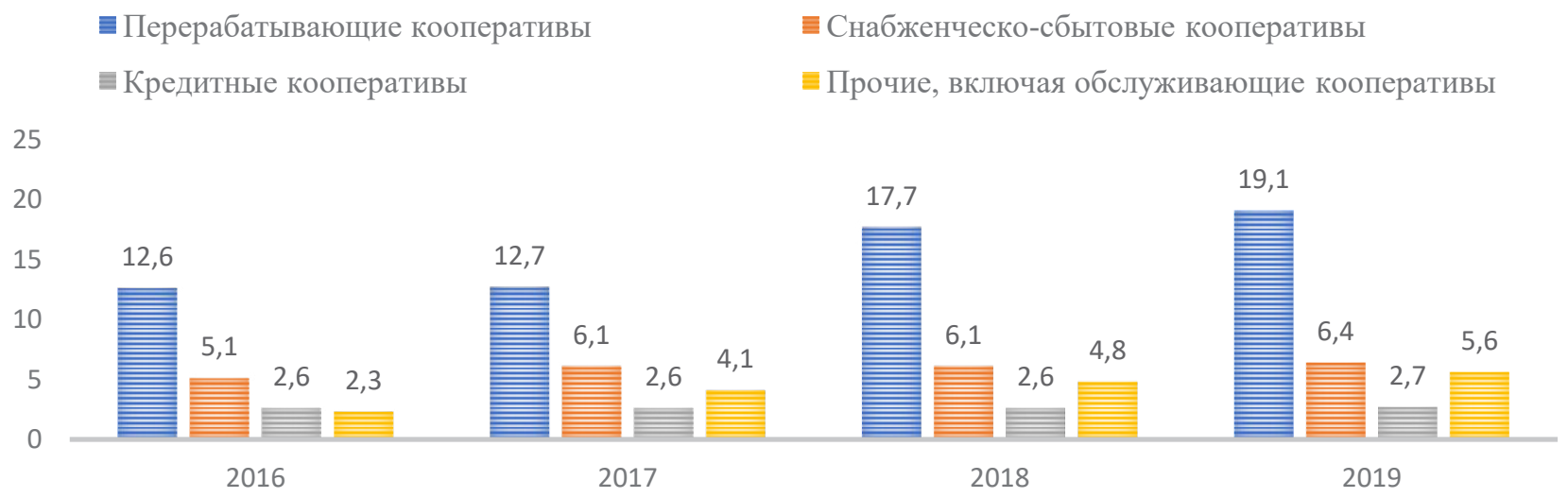

Puc. 2. Стоимость продукции СХК

вместная аренда оборудования, что не является в строгом смысле сельскохозяйственным производством [2, с. 69]. И действительно, основная область проблематике лежит в области сбыта и переработки. Небольшие фермерские хозяйства осуществляют производство продукции силами нескольких человек (2-3 человека могут обслуживать несколько десятков голов КРС; труда двух человек достаточно для обслуживания кролиководческой фермы с маточными поголовьем 200 особей и др.). Однако, фермеры, как правило, не имеют навыков сбыта и испытывают серьезные сложности с переработкой продукции. Именно поэтому производственные кооперативы по отношению к потребительским имеют столь незначительную долю.

Несмотря на рост численности кооперативов и повышение объемов продукции, в структуре сельского хозяйства кооперативы занимают незначительное место (табл. 1). Так, в 2019 году стоимость продукции кооперативов составила $0,58 \%$ от стоимости продукции хозяйств всех категорий, что свидетельствует о недостаточном развитии кооперации в России.

Безусловно, темпы роста объема продукции потребительских СXК (темпы роста за период
2016-2019 годов составили 149,5\%) и объема продукции хозяйств вех категорий (темпы роста за период 2016-2019 годов составили 113,4\%). Однако, высокая динамика относительных показателей обусловлена первым этапом роста и появлением системной государственной поддержки. Полагаем, что в дальнейшем при аналогичных мерах объем продукции СХК будет так же колебаться в пределах одного процента.

Следующий шаг на пути развития кооперативов - укрупнение структур. Н.П.Воронина указывает, что по мере развития российских сельскохозяйственных кооперативов «они подлежат объединению в вертикальные местные, региональные и федеральные кооперативные структуры. Критерии вертикальной интеграции - отраслевой, территориальный и территориально-отраслевой» [1, с. 3]. Отметим, что при формировании крупных структур они могут стать институциональными субъектами политической системы (как профсоюзы, органы муниципальной власти и др.), что позволит отстаивать интересы кооперативов в политическом пространстве.

Интерес представляет вопрос о структуре самих потребительских СХК. Динамично разви-

Таблица 1. Продукция CX по категориям хозяйств

\begin{tabular}{|l|c|c|c|c|}
\hline & $\begin{array}{c}2016 \text { год } \\
\text { (млрд. руб) }\end{array}$ & $\begin{array}{c}2017 \text { год } \\
\text { (млрд. руб) }\end{array}$ & $\begin{array}{c}2018 \text { год } \\
\text { (млрд. руб) }\end{array}$ & $\begin{array}{c}2019 \text { год } \\
\text { (млрд. руб) }\end{array}$ \\
\hline Хозяйства всех категорий & 5112,3 & 5109,5 & 5348,8 & 5801,4 \\
\hline Сельскохозяйственные организации & 2818,4 & 2818,5 & 3022,1 & 3348,4 \\
\hline Хозяйства населения & 1659,2 & 1655,4 & 1656,7 & 1659,7 \\
\hline КФХ & 634,7 & 635,6 & 670,0 & 793,3 \\
\hline Потребительские СХК & 22,6 & 25,5 & 31,2 & 33,8 \\
\hline
\end{tabular}


ваются перерабатывающие и прочие виды кооперативов. В ст. 2 ФЗ «О сельскохозяйственной кооперации» указаны следующие виды потребительских СХК:

- Перерабатывающие кооперативы;

- Сбытовые (торговые) кооперативы;

- Обслуживающие кооперативы;

- Снабженческие кооперативы;

- Растениеводческие кооперативы;

- Животноводческие кооперативы;

- Иные кооперативы.

Очевидно, что законодатель не руководствовался строгими критериями классификации. Отметим, что речь идет именно о потребительских кооперативов, не связанных напрямую с производством продукции. Среди всего открытого перечня кооперативов отдельно следует сказать об обслуживающих кооперативах. В мировой практике под сельскохозяйственными обслуживающими кооперативами понимают кооперативы, созданные производителями сельскохозяйственной продукции для совместного обслуживания производственных нужд своих хозяйств на всех этапах производственного цикла с целью повышения уровня их доходов [9, с. 73]. Характер обслуживающих кооперативов может разниться в зависимости от поставленных задач, однако общим является поддержание производственных нужд. Поддержка обслуживающих кооперативов представляет большую значимость, поскольку в рамках этих кооперативов могут решаться такие важные задачи, как, в частности, обеспечение собственного производства комбикорма, закупка племенного скота (в том числе из зарубежных стран).

Список видов потребительских кооперативов открытый, однако в экономической практике иные кооперативы представлены в основном кредитными кооперативами.

Создание кредитных потребительских СХК допускается действующим законодательством, однако их число невелико, и фермеры при возникновении потребности в кредитных средствах обращаются в банки. Практика функционирования кредитных кооперативов долгое время поддерживается властями отдельных регионов. Так, к примеру, С.А.Пахомчик, Т.В.Клыкова пишут, что в Тюменской области действуют более двух десятков кредитных кооперативов. Подавляющую часть средств фондов кредитования составляют выделенные им бюджетные средства [6, с. 13]. Собственно, основная особенность со- временных кредитных кооперативов - оперирование бюджетными средствами. Кредитные организации не заинтересованы в появлении кредитных кооперативов, поддержка со стороны банковской системы не производится. Вместе с этим, выделение бюджетных средств для нужд кооперативов вряд ли станет повсеместной практикой. Решение проблемы может лежать в плоскости новых технологий - а именно технологий блокчейна и цифровой валюты. Технология распределенных реестров для кредитной кооперации способна усилить конкурентные преимущества, основанные на кооперативных принципах взаимопомощи, солидарности, прозрачности, доверия, демократического управления [3, с. 69]. Поскольку оперирование криптовалютой является недопустимым (в России запрещено использование криптовалюты в качестве средства платежа), полагаем, что цифровой рубль будет являться безальтернативным решением. В настоящее время законодатель продолжает регулирование обращения цифровых денег, и в случае разработки и принятия закона о цифровом рубле (реализацию подобного плана Правительство намерено произвести в ближайшей перспективе и опорой на китайскую практику) появится возможность пересмотреть технологические основы деятельности кредитных кооперативов.

Нельзя не сказать об отдельной проблеме, которая разрешается посредством создания кооперативов - это проблема сбыта [13]. Многие фермеры имеют навыки по производству продукции, однако не обладают достаточной осведомленностью о технологиях маркетинга. При реализации региональных программ количество доступных для сбыта каналов возросло. В настоящее время фермерам доступны следующие каналы сбыта продукции сельскохозяйственный потребительских кооперативов:

- Федеральные торговые сети;

- Нестационарные торговые объекты (ярмарки);

- Магазины системы Центросоюза РФ;

- Собственные магазины (сети);

- Закупки крупнейших заказчиков у субъектов МСП;

- Оптово-распределительные центры.

В случае, если участники кооперативов получат устойчивые возможности для сбыта продукции, это позволит существенно увеличить объемы производства. Ввиду высокой цены 
фермерской продукции требуется производство крупными партиями для увеличения выручки и снижения маржи. Фермеры, как правило, производят продукцию небольшими партиями и ориентированы на норму прибыли 30-50\%. При получении гарантированного (по возможности) сбыта фермеры смогут увеличить объемы продукции и поставлять ее по более низким ценам (в небольших оптимизированных хозяйствах возможно многократное увеличение производимой продукции при сравнимых трудовых за- тратах).

Таким образом, в последние годы процесс развития сельскохозяйственной кооперации сдвинулся с мертвой точки, что обусловлено в первую очередь разработкой и реализацией государственных программ. Полагаем, что при расширении каналов сбыта, укрупнении кооперативов и развитии инициативы сельского населения возможно существенное увеличение доли продукции, поставляемой СХК.

\section{Библиографический список}

1. Воронина Н.П. Сельскохозяйственная кооперация: проблемы правового регулирования // Сельское хозяйство. 2019. № 2. С. 1-6.

2. Иншаков А.А. Сущностные качества сельскохозяйственной кооперации // Инновации и инвестиции. 2017. № 5. С. 68-72.

3. Коробейникова О.М., Коробейников Д.А., Голубева Е. В., Чернованова Н.В.Цифровые инновации для кредитной кооперации // Научный вестник: финансы, банки, инвестиции. 2020. № 1. С. 63-71.

4. Лукичев П.М.Сельскохозяйственная кооперация и её социальная роль в России // Известия СанктПетербургского государственного аграрного университета. 2018. № 51. С. 231-235.

5. Меры поддержки сельскохозяйственной кооперации, реализуемые $\mathrm{AO}$ «Корпорация «МСП»: предварительные итоги 2020 г. [Электронный ресурс] // Режим доступа: www.corpmsp.ru (дата обращения 11.02.21).

6. Пахомчик С.А., Клыкова Т. В. Развитие сельскохозяйственной кооперации Тюменской области после принятия ФЗ «О сельскохозяйственной кооперации» // Вестник Курганской ГСХА. 2017. № 1. С. 12-14.

7. Сельское хозяйство, охота и лесное хозяйство [Электронный ресурс] // Росстат. URL: https://rosstat.gov.ru/ enterprise_economy (дата обращения 11.02.20).

8. Стандарт деятельности центров компетенций в сфере сельскохозяйственной кооперации и поддержки фермеров (утв. проектным комитетом по национальному проекту «Малый бизнес и поддержка индивидуальной предпринимательской инициативы», протокол от 21.03.2019 № 1) // Доступ из СПС «Гарант».

9. Стильник В.В. Особенности сельскохозяйственных обслуживающих кооперативов // Статистика и экономика. 2013. № 2. С. 71-74.

10. Федеральный закон «О сельскохозяйственной кооперации» от 08.12.1995 № 193-Ф3 (ред. от 08.12.20) // С3 РФ от 11 декабря 1995 г., № 50, ст. 4870.

11. Dudin M.N., Lyasnikov N. V., Sekerin V.D., Gorokhova A.E. HISTORICAL ASPECTS OF GLOBAL TRANSFORMATION OF ENGINEERING THOUGHT IN INDUSTRY AND AGRICULTURE IN THE CONTEXT OF CHANGING THE TECHNOLOGICAL MODES // American-Eurasian Journal of Sustainable Agriculture. 2014. T. 8. № 6. C. 17-22

12. Sekerin V.D., GorokhovaA.E., Dudin M.N., Shibanikhin E.A., BalkizovM.H. GREEN BUILDING: TECHNOLOGIES, PROSPECTS, INVESTMENT ATTRACTIVENESS // International Journal of Civil Engineering and Technology. 2018. T. 9. № 1. C. 657-666

13. Trubilin A.I., GaydukV.I., Belkina E.N., Kalitko S.A., GorokhovaA.E. INFRASTRUCTURE OF THE REGIONAL AGRIFOOD MARKET: PECULIARITIES OF FUNCTIONING AND METHODS OF IMPROVEMENT // Espacios. 2017. T. 38. № 33. C. 41 